\title{
Hurry up and wait
}

$M$ artin is in his late eighties. He was admitted to hospital for an acute illness - partly, as it turns out, caused iatrogenically, a change in drug dosage. He and his wife had been living on their own, getting by well enough, until he was rushed to hospital close to death. He was treated quickly and well. He "recovered."

Martin's doctors practise "save-alife-and-on-to-the-next" medicine. They fix the mechanical problem and lose interest in the patient's recovery. Head 'em on and move 'em out cowboy. But Martin can't be moved out: he's got a long way to go. He languishes "off active service" in an acute general medicine ward, waiting for geriatric rehab. He becomes deconditioned to the point of being bedridden. The miscommunications are horrific. He can't go to rehab unless he has a placement set up in assisted living. His wife had understood that he'd go to rehab first, and then they'd see what level of living assistance he needs. Meanwhile the social work staff wonder why she is so passive, and he lies there with no physio, no OT and barely enough nursing care for basic needs, losing the strength to get out of bed. Without his elderly wife waiting by his side he would lie in shit for hours.

Martin has cataracts. This man whose life is reading the newspaper no longer has the eyesight to see his food. It is put down, and taken away uneaten. He is refused a preoperative assessment for cataract surgery because they "don't do that on inpatients." How is be supposed to know the arcane rules? Who looks out for all of him, where's his doctor? His wife doesn't know that only the hospital team is "allowed" to see her husband, the provincial health plan having given up paying family doctors for supportive care long ago. On the ward, the team changes every two weeks: new attending, new residents. They move him to another floor; he gets a new social worker. Since when do social workers take care of floors? With every change of room, with every change in staff assignment, there's a progressive disappearance of the person. The Martin that is handed on is assumed to be the Martin that always was; everyone accepts his present, apparent capacity as authentic.

The physiotherapist starts to see him, but she can't come every day; twice a week, she cajoles him for half an hour. Martin's wife pleads with him to do his exercises on his own. But he can't seem to manage it. His spirit declines. He

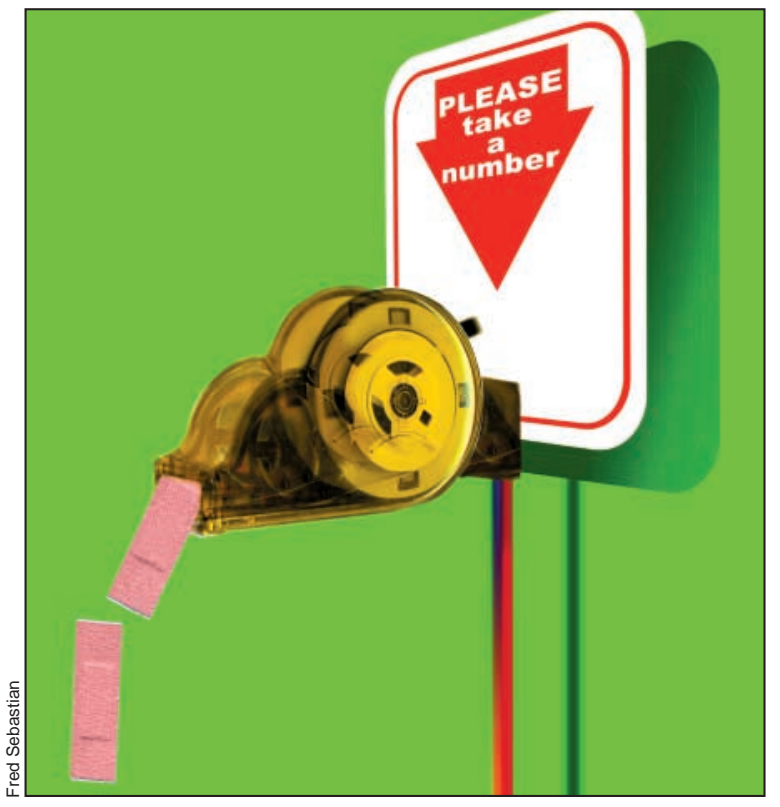
sleeps 22 hours one day, refuses food, won't try to get out of bed. No one seems to notice.

When she sits at home at night, Martin's wife wonders how her husband got so sick. In the hospital, it doesn't seem so strange. No one asks Martin how he is feeling, if he is depressed, how he feels about being ill, if he wants to carry on or give up.

Medicine has become an industrial process, managed by industrial methods. But people are not commodities, the objects of a manufacturing process. Rooms, floors, teams all change based on management needs, not patient needs.

Nothing happens with alacrity except the reaction to acute emergency. We are good Canadians, we queue up uncomplainingly, accept waiting a year for cataract surgery, as Martin did, meanwhile becoming disabled by blindness. We accept an eight-week wait for a rehab bed, a month for palliative care if we last that long. We accept that the physiotherapist is too busy to see each patient daily.

We accept, because care is "free," that the price to pay is time. We accept a wait of a month to see a breast surgeon, another month for a biopsy, and yet another for definitive treatment. It makes no difference to mortality, say the epidemiologists, true enough, and the health care managers, who do not really know the true nature of the business they are managing, are only too eager to allow the waiting if it means they do not need to spend more precious, and for all intents and purposes rationed, dollars. No one seems to know or care about the anxiety and mental anguish the patient and family feel during this torturous delay.

The American system is different, not better. If you have money or insurance, you have the best care with due haste. If you are uninsured, you'll be bankrupted by an appendectomy. This is no way to treat a population. Somewhere in the middle is the model. Good care at good speed.

Martin is still waiting.

\section{Robert M. Bernstein}

Visiting Professor

Boston University Medical Center

Boston, Mass.

Professor

Department of Family Medicine

University of Ottawa

Ottawa, Ont. 